\title{
Awareness and prevalence on computer vision syndrome among medical students: A cross-sectional study
}

\author{
Sughandha Garg', Debayan Mallik², Arun Kumar ${ }^{3}$, Rajasri Chunder ${ }^{4}$, Ajay Bhagoliwal ${ }^{5}$ \\ ${ }^{1}$ Assistant Professor, Department of Pharmacology, Jagannath Gupta Institute of Medical Sciences and Hospital, \\ Buita, Budge Budge, Kolkata- 700137, 2 2 Assistant Professor, Department of Community Medicine, Jagannath Gupta \\ Institute of Medical Sciences and Hospital, Buita, Budge Budge, Kolkata- 700137, ${ }^{3}$ Professor and Head, Department \\ of Biochemistry, Jagannath Gupta Institute of Medical Sciences and Hospital, Buita, Budge Budge, Kolkata- 700137, \\ ${ }^{4}$ Professor and Head, Department of Anatomy, Jagannath Gupta Institute of Medical Sciences and Hospital, Buita, \\ Budge Budge, Kolkata- 700137, ${ }^{5}$ Ex. Professor, Department of Community Medicine, Rama Medical College Hospital \\ and Research Center, Kanpur, Uttar Pradesh
}

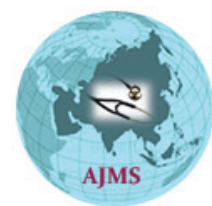

\section{A B S T R A C T}

Background: Computers have significantly impacted cognitive, social, physical and various other aspects of the modern daily lives of computer users, especially among internet users. Our life is inseparable from the internet, e.g., chatting, online shopping, gaming, video conferencing, and emailing. In the modern day, nearly every job is done sitting in front of a computer. Majority of the day is spent on the computer either working or for recreational purposes. Consequently, the effects of computer use on eyes and vision has increased too. This study will review the factors relating to eye and vision problems amongst students and its association with computer work and provide recommendations for preventing or reducing their development. Aims and Objectives: The aim of the current study was to estimate the prevalence of computer vision syndrome, its knowledge and application among medical students. Materials and Methods: This was a cross-sectional study, which was carried out amongst the MBBS students $\left(1^{\text {st }}, 2^{\text {nd }}\right.$ and $3^{\text {rd }}$ year $)$ of Rama Medical College Hospital and Research Center, Kanpur, India. The data was collected between January 2017 to March 2017. Students who gave their consent were taken up for the study. A pretested, semi-structured questionnaire was used to collect the data. Results: A total of 214 medical students participated and majority of them were below 22 years of age. The prevalence of Computer Vision Syndrome was found to be $83 \%$ $[95 \% \mathrm{Cl}=67.9 \%-91.6 \%]$. More than $70 \%$ students spend up to 4 hours in front of computer. Roughly $40 \%$ knowledge of Computer Vision Syndrome, but only $10 \%$ took any measures to prevent the disease. And those who had symptoms experience them within 2-3 hours of computer use. Majority of them complained of having watery eyes and blurred vision. Conclusion: A significant proportion of students do manifests Computer Vision Syndrome and denotes that the health of the people working on the computers should be emphasized as a field of concern in public health. These are young kids and having this syndrome so early in life will have a detrimental effect on their health in future. Hence the stakeholders involved, needs to be sensitized regarding the importance of the regular eye and health check-ups and proper rest to the eyes. Further research is recommended to know the depth of the problem as it has the potential to become a modern-day pandemic.

Key words: Computer Vision Syndrome; CVS prevalence; Medical students; Dry eyes; Watery eyes; Effects of computer

\section{Access this article online}

Website:

http://nepjol.info/index.php/AJMS DOI: 10.3126/ajms.v12i9.37247

E-ISSN: 2091-0576

P-ISSN: 2467-9100

Copyright (c) 2021 Asian Journal of Medical Sciences

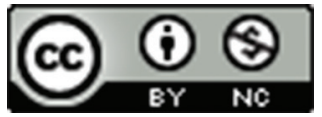

This work is licensed under a Creative Commons Attribution-NonCommercial 4.0 International License. 


\section{INTRODUCTION}

Computers have become an essential part of human life. Everyone needs to use computer for some reason or the other. Since the advent of games, various computer programs, shopping etc., needs to use the computers extended to such an extent, that various jobs are now based solely on use of computers. Since the computer is involved with vision and eyes, it has effect on eye and surrounding muscles too. The symptoms of computer vision syndrome (CVS) are: headache, tiredness, irritation of eyes, dryness of eyes, redness, heaviness, watering etc. Most of these symptoms are due to dryness of eyes which is created by the monitor light, and reduced blinking. The computer part that has major effect on eyes is the "monitor". The monitor emits light which causes of evaporation of tear film and thus causes dryness. Tear film is a thin film of liquid which covers the surface of eye. This wets the eye and nourishes it. If its depleted, eyes become dry and irritable. The light from the monitor also irritates the surface of eye. Normally we blink about 15 times per minute. Blink is very essential as it reforms the tear film which breaks up before the blink. Blinking occurs involuntarily without our knowledge. During computer usage, the blink rate falls down, as we are focusing on the monitor. This reduced blinking exposes the eye surface to environment for more than normal time. Thus, the tear film gets evaporated, leading to dryness.

With the increased use of computers in the life of a student, it has brought about the development of a number of health concerns. Many individuals who work at a computer report multiple complaints and symptoms, including ocular discomfort, muscular strain and stress. The level of discomfort appears to increase with the amount of computer use. Visual discomfort and related symptoms occurring in computer users must be recognized as a growing health problem. The complex of eye and vision problems related to near work experienced during computer use has been termed "computer vision syndrome". Many individuals who work at a computer experience eye-related discomfort and/or visual problems. However, based on current evidence it is unlikely that the use of computers causes permanent changes or damage to the eyes or visual system. ${ }^{1-4}$

Computers have significantly impacted cognitive, social, physical and various other aspects of the modern daily lives of computer users, especially among internet users. Our life is inseparable from the internet, e.g., chatting, online shopping, gaming, video conferencing, and emailing. In the present-day situation, nearly every job is done sitting in front of a computer. Majority of the day is spent on the computer either working or browsing or googling. The medical students have to sit between 4-5 hours daily to do reference study from Google or YouTube or other online education companies like Marrow etc. At times, they browse for recreational and entertainment purposes too. A student spends roughly more than $1 / 4^{\text {th }}$ of the day over computer itself. Consequently, the effects of computer use on eyes and vision has increased too. This study will review the factors relating to eye and vision problems associated with computer work and provide recommendations for preventing and reducing the development of Computer Vision Syndrome in students.

\section{Aims and objectives}

The aim of the current study was to estimate the prevalence of computer vision syndrome, its knowledge and application among medical students.

\section{MATERIALS AND METHODS}

This was a cross-sectional study, which was carried out amongst the medical students $\left(1^{\text {st }}, 2^{\text {nd }} \& 3^{\text {rd }}\right.$ year $)$ of Rama Medical College and Hospital, Kanpur, India. The data was collected between January 2017 to March 2017. Students who gave their consent were taken up for the study. A pretested, semi-structured questionnaire was used to collect the data.

A pretested, semi-structured questionnaire was used to collect the data. The study was pre-approved by the Ethical committee of this institution.

\section{The Inclusion criteria were}

1. Aged 18 and above.

2. Medical student of the college.

3. Average usage of Computer for minimum of 2 hours daily.

4. History of Computer usage of more than 3 years.

\section{The Exclusion criteria were}

1. Not a Medical student of the college.

2. Not willing to participate.

3. Individual not present during the interview.

4. Using computer less than 2 hours daily.

5. History of Computer usage less than 3 years

After obtaining verbal and informed written consent, subjects were given self-administered questionnaire and the data was collected. All participants, who met the inclusion criteria had been included in the study. Participants who didn't meet the criteria were excluded from this study. The collected data was analyzed by using SPSS software (Trial Version) 23.0. 


\section{RESULTS}

The present study included 214 medical students out of which 134 were male and 80 were female and $86.92 \%$ were below 22 years of age (Table 1). Regarding time spent by students in front of a computer and $49(22.9 \%)$ reported spending between $>2-<3$ hours, $64(25.23 \%)$ spent between $>3-<4$ hours, $54(25.23 \%)$ spent between $>4-<6$ hours, $37(17.29 \%)$ spent between $>6-<8$ hours and $10(4.67 \%)$ spent more than 8 hours on computer daily. Mean duration was calculated to be $4.75+2.34$ hours (Table 2). When asked about knowledge of Computer Vision Syndrome, 39.25\% responded to be having the knowledge but only $11.68 \%$ were actually using them. Fisher's Z test was used, where $Z$ was calculated to be 6.49 and $\mathrm{p}$ value was 0.001 which is statistically highly significant (Table 3). When asked about the symptoms, the students responded that $38(17.76 \%)$ were sensitive to light, $24(11.2 \%)$ were having redness of eyes, $32(14.95 \%)$ had sensation of having something in the eyes, $4(1.87 \%)$ had difficulty in wearing contact lens, 28 (13.08\%) had difficulty in night time driving, 68 (31.78\%) had watery eyes and $54(25.23 \%)$ had blurred vision or eye fatigue. Fisher's exact test was used and p value was calculated to be 0.0484 , which is statistically significant (Table 4). When we asked about the time spent on computer after which start experiencing symptoms of Computer Vision Syndrome, we found out that $4(1.87 \%)$ experience symptoms within 1 hour of use of the computer, $45(21.03 \%)$ experience symptoms after 1 hour to 2 hours of use of the computer, $56(26.17 \%)$ after 2 to 4 hours of use of the computer, $73(34.11 \%)$ after 4 to 6 hours of use of computer, $4(1.87 \%)$ after 6 to 8 hours of use of computer, $8(3.74 \%)$ experience symptoms after using the computer for more than 8 hours. Single sample t-test was used and $\mathrm{p}$ value was calculated to be $<0.00001$, which is statistically highly significant (Table 5). The prevalence of Computer Vision Syndrome was found to be 83\% [95\% CI $=67.9 \%-91.6 \%]$.

Table 1: Age group wise gender distribution of the students

\begin{tabular}{lccc}
\hline Age group & Male & Female & Total \\
\hline $17-21$ years & $114(53.27 \%)$ & $72(33.64 \%)$ & $186(86.92 \%)$ \\
$>22$ years & $20(9.35 \%)$ & $8(3.74 \%)$ & $28(13.08 \%)$ \\
Total & $134(62.62 \%)$ & $80(37.38 \%)$ & $214(100 \%)$ \\
\hline
\end{tabular}

\section{DISCUSSION}

In our study, we found that $62.62 \%$ [n=214] $(134 / 214)$ respondents were male and $37.38 \%(80 / 214)$ were female, whereas Bhanderi et al., in his study found that $66 \%$ of the respondents in his study were male and 34\% were female, which was similar to our study. ${ }^{5}$ In another study by Mohan Kumar et al., it was found that $76.6 \%$ were males and 23.3 $\%$ were female, which was not similar to our studies. ${ }^{6}$ In another study by Das et al., it was observed that $45.7 \%$ were females and $54.3 \%$ were females which was not at all similar to our studies. ${ }^{7}$ In the study conducted by Kumar et al., it was seen that male and female participants were $50 \%$ each which was again not similar to our studies. ${ }^{8}$ In the study conducted by Bhanderi et al., $66 \%$ of his study subjects were below the age group of 25 years and mean age was found to be 25.04, whereas, in our study, we found that $86.92 \%$ belongs to $17-21 \%$ age group, which was not similar to our study. ${ }^{5}$ In the study conducted by Das et al., it was observed that $38.4 \%$ were in the age group of $20-22$ years, $46.9 \%$ were in the age group of $23-25$ years, $14.7 \%$ were in the age group of 26-28 years which was not similar to our studies. ${ }^{7}$ In a similar study by Arumurgam et al., they found that mean duration of daily computer usage was $4.27 \pm 2.78$ hours, whereas, in our study, we found mean duration of daily usage of computer to be $4.75 \pm 2.34$ hours, which was similar to our study.?

In the study conducted by Kumar et al., on medical students, it was found that only $20 \%$ were aware of the symptoms of CVS and $80 \%$ were not aware of them, whereas in our study we found out that $39.25 \%$ were aware of it and $60.75 \%$ were not aware of it. $^{8}$ In the study conducted by Mohan Kumar et al., it was observed that $41.6 \%$ were aware and $58.4 \%$ were not aware of the symptoms of CVS which similar to our studies. ${ }^{6}$ We also tried to find out the relationship between computer use and symptoms of CVS and observed that $17.76 \%$ had sensitivity light out of which $52.63 \%$ developed them with 5 years of computer use. Eleven-point two percent had eye redness out of which $54.16 \%$ had developed in them with 5 years of computer use. Those who had difficulty in wearing contact lens had them within the first 5 years of computer usage. However, after extensive research we couldn't find any similar study. In our study we observed the duration of computer use after which participants had one or the other symptoms of CVS and it was found that

Table 2: Students using computer on daily basis

\begin{tabular}{|c|c|c|c|c|c|c|}
\hline & $>2-<3$ hours & $>3-<4$ hours & $>4-<6$ hours & $>6-<8$ hours & $>8$ hours & Total \\
\hline Male & $30(14.02 \%)$ & $33(15.42 \%)$ & $40(18.69 \%)$ & $21(9.81 \%)$ & $10(4.67 \%)$ & $134(62.62 \%)$ \\
\hline Female & $19(8.88 \%)$ & $31(14.48 \%)$ & $14(6.54 \%)$ & $16(7.48 \%)$ & $0(0 \%)$ & $80(37.38 \%)$ \\
\hline Total & $49(22.9 \%)$ & $64(29.9 \%)$ & $54(25.23 \%)$ & 37 (17.29\%) & $10(4.67 \%)$ & $214(100 \%)$ \\
\hline
\end{tabular}




\begin{tabular}{|c|c|c|}
\hline & Yes & No \\
\hline Having knowledge of preventive measures & $84(39.25 \%)$ & $130(60.75 \%)$ \\
\hline Using preventive measures to prevent CVS & 1. $11.68 \%)$ & $189(88.32 \%)$ \\
\hline Fisher's Z test & \multicolumn{2}{|c|}{$\begin{array}{c}Z=6.49 \\
p=0.001\end{array}$} \\
\hline
\end{tabular}

\begin{tabular}{lccc} 
Table 4: Relationship between the duration of computer use in years and CVS symptoms & Total \\
\hline & Less than $\mathbf{5}$ years & $\mathbf{5}$ years and above & $38(17.76 \%)$ \\
\hline Sensitivity to light & 20 & 18 & $24(11.2 \%)$ \\
Eye redness & 13 & 11 & $32(14.95 \%)$ \\
Sensation of having something in your eyes & 15 & 0 & $4(1.87 \%)$ \\
Difficulty in wearing contact lenses & 4 & 16 & $28(13.08 \%)$ \\
Difficulty in night-time driving & 12 & 43 & $68(31.78 \%)$ \\
Watery eyes & 25 & 23 & $54(25.23 \%)$ \\
Blurred vision or eye fatigue & 15 & $\mathrm{p}=0.0484$ & \\
Fisher's Exact test & &
\end{tabular}

\begin{tabular}{|c|c|c|c|c|c|c|c|c|}
\hline $\begin{array}{l}\text { Hours spent } \\
\text { on computer }\end{array}$ & $<1$ hour & $>1-<2$ hours & $>2-<4$ hours & $>4-<6$ hours & $\begin{array}{l}>6-<8 \\
\text { hours }\end{array}$ & $>8$ hours & $\begin{array}{l}\text { Never experiences } \\
\text { any symptoms }\end{array}$ & Total \\
\hline $\begin{array}{l}\text { Participants } \\
\text { having } \\
\text { symptoms }\end{array}$ & $4(1.87 \%)$ & $45(21.03 \%)$ & $56(26.17 \%)$ & $73(34.11 \%)$ & $4(1.87 \%)$ & $8(3.74 \%)$ & $24(11.21 \%)$ & 214 \\
\hline $\begin{array}{l}\text { Single sample } \\
\text { t-test }\end{array}$ & \multicolumn{8}{|c|}{$p=<0.00001$} \\
\hline
\end{tabular}

$1.87 \%$ had them within one hour of computer use, $21.03 \%$ had them within 1-2 hours of computer use, $26.17 \%$ had them within 2-4 hours of computer use, $34.11 \%$ had them within $4-6$ hours of computer use and $1.87 \%$ had them within 6-8 hours of computer use and 3.74\% had them after using the computer for more than 8 hours. However, $11.21 \%$ had no symptoms at all. We searched extensively but couldn't found any study similar to this.

We found in our study that $3 / 4^{\text {th }}$ of the respondents had Computer Vision Syndrome. Magnitude of visual problems was found to be directly related to average computer hours per day.

\section{Limitations of this study}

The participants of this study were taken from one medical college and on a small population. Despite the limitations of this research, the results would serve as a knowledge base on which to build strategies for improving Computer Vision Syndrome knowledge. The results would be useful for policy makers, programme planners, public health experts and eye care practitioners. However, further research of this nature about Computer Vision Syndrome should be conducted in computer-using institutions in other parts of India and then amongst the population at large.

\section{CONCLUSION}

In conclusion, $83 \%$ of the students were found to have Computer Vision Syndrome. This is a significant proportion and denotes that rational use of computer should be emphasized otherwise it will become a field of concern in public health. We strongly recommend that the following steps to be taken to reduce the occurrence and prevention of dry eye and eye related problems.

\section{Recommendations}

We strongly recommend that the following steps to be taken to reduce the occurrence and prevention of dry eye and eye related problems.

1. Since the world is getting digital and every resource is available over internet, people are bound to spend most of their time on computers. Thus, Computer Vision Syndrome is going to be the major side effects of it. So, special instructions/guidelines should be issued by the Government for its prevention and awareness.

2. Breaks should be taken for at least 10 minutes after every 1 hour of computer usage.

3. Promotion of physical activity should be advocated and encouraged by the school and colleges. 


\section{ACKNOWLEDGMENTS}

The author takes the privilege to thank all participants in this study and everyone involved in carrying out this study.

\section{REFERENCES}

1. National Research Council (US) Panel on Impact of Video Viewing on Vision of Workers and National Research Council (US) Committee on Vision. Video Displays, Work, and Vision. National Academies Press (US), 1983

https://doi.org/10.17226/169

2. Council on Scientific Affairs, American Medical Association. Health Effects of Video Display Terminals. JAMA. 1987;257(11):1508-1512.

https://doi.org/10.1001/jama.1987.03390110084032

3. Cole BL, Maddocks JD and Sharpe K. Effects of VDUs on the eyes: Report of a 6-year epidemiological study. Optom Vis Sci. 1996;73(8):512-528.

https://doi.org/10.1097/00006324-199608000-00001

4. Mutti DO and Zadnik K. Is computer use a risk factor for myopia? J Am Optom Assoc. 1996;67(9):521-530.
5. Bhanderi DJ, Choudhary S and Doshi VG. A community-based study of asthenopia in computer operators. Indian J Ophthalmol. 2008;56(1):51-55.

https://doi.org/10.4103/0301-4738.37596

6. Mohan Kumar BK, Thiruvalluvan GT and Arjunan MK. Effectiveness on knowledge about computer vision syndrome among medical coding trainee in medical coding training institute in urban Chennai, Tamil Nadu - A cross- sectional study. J Family Med Prim Care. 2021; 10:228-231. https://doi.org/10.4103/jfmpc.jfmpc_1151_20

7. Das $S$ and Dubey RS. Computer Vision Syndrome among Medical Undergraduates at MRIMS, Hyderabad, Telangana. Ophthalmology and Allied Sciences.2018; 4 (2): 83-86.

8. Kumar BM, Thiruvalluvan $G$ and Arjunan M. Effectiveness on knowledge about computer vision syndrome among medical coding trainee in medical coding training institute in urban Chennai, Tamil Nadu - A cross- sectional study. Journal of Family Medicine and Primary Care. 2021; 10(1): 228. https://doi.org/10.4103/jfmpc.jfmpc_1151_20

9. Arumugam S, Kumar K, Subramani R and Kumar S. Prevalence of Computer Vision Syndrome among Information Technology Professionals Working in Chennai. World J Med Sci. 2014;11(3):312-314.

\section{Author's contribution:}

SG- Principal Investigator, Concept and design of the study, prepared the first draft of manuscript; DM-Statistical analysis and interpretation, manuscript preparation and revision; AK-Interpretation of results, literature review and manuscript preparation; RC- Collection and compilation of data, coordination; AB-Concept, coordination, review of literature and manuscript preparation. Study was approved by all authors.

Work attributed to:

Jagannath Gupta Institute of Medical Sciences and Hospital, Buita, Budge Budge, Kolkata- 700137.

Orcid ID:

Dr. Sughandha Garg- (D) https://orcid.org/0000-0001-5746-8374

Dr. Debayan Mallik- id https://orcid org/0000-0002-1429-5896

Dr. Arun Kumar- (i) https://orcid.org/0000-0002-8800-0296

Dr. Rajasri Chunder- (10 https://orcid.org/0000-0002-1938-1662

Dr. Ajay Bhagoliwal- (iD https://orcid.org/0000-0001-6869-449X

Source of Funding: None, Conflict of interest: None. 